\title{
Transcription factors
}

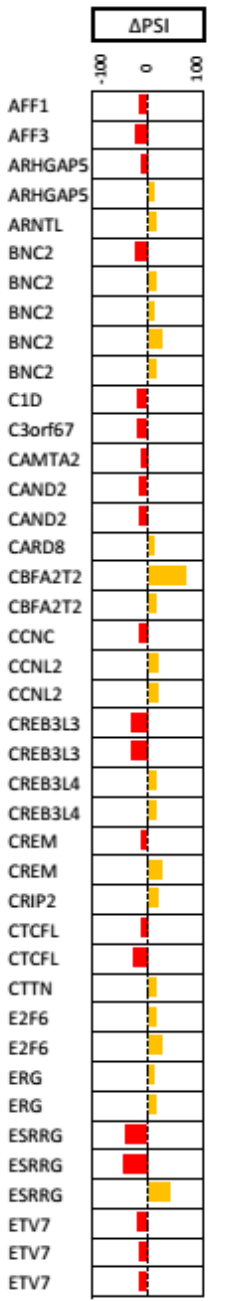

\begin{tabular}{l|l|l} 
& \\
\end{tabular}

\begin{tabular}{|c|c|c|}
\hline & & PSSI \\
\hline & 8 & - 8 \\
\hline MO3 & & 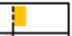 \\
\hline RRFIP1 & & \\
\hline RFIP2 & & 8 \\
\hline MAP2 & & \\
\hline ECOM & & E \\
\hline MECOM & & ! \\
\hline MLLT10 & & $!$ \\
\hline MLLT10 & & 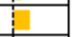 \\
\hline MLLT10 & & E \\
\hline XIPL & & 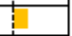 \\
\hline MLXIPL & & 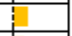 \\
\hline MORF4L & & 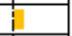 \\
\hline MORF 4 L & & $i$ \\
\hline MSS51 & & \\
\hline MYB & & $i$ \\
\hline MYB & & \\
\hline MYB & & $=$ \\
\hline MYB & & 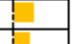 \\
\hline $\begin{array}{l}\text { MYBL1 } \\
\text { NCOA3 }\end{array}$ & & 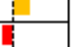 \\
\hline NCOR1 & & E \\
\hline NCOR1 & & 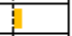 \\
\hline NFYA & & \\
\hline NOD2 & & F \\
\hline NOD2 & & 8 \\
\hline NPAS1 & & \\
\hline $\begin{array}{l}\text { NR1H4 } \\
\text { NR113 }\end{array}$ & & \\
\hline NR113 & & E \\
\hline $\mathrm{NR} 2 \mathrm{C} 1$ & & \\
\hline $\mathrm{NR} 2 \mathrm{C} 1$ & & \\
\hline $\mathrm{NR} 2 \mathrm{C} 1$ & & \\
\hline $\begin{array}{l}\mathrm{NR} 3 \mathrm{Cl} 1 \\
\mathrm{NR3C2}\end{array}$ & & 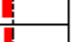 \\
\hline PAXS & & 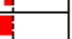 \\
\hline PAX5 & & $\bar{E}$ \\
\hline PAXS & & 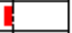 \\
\hline PAX8 & & : \\
\hline PAX8 & & \\
\hline $\begin{array}{l}\text { PDLIM3 } \\
\text { PDUMM }\end{array}$ & & \\
\hline
\end{tabular}
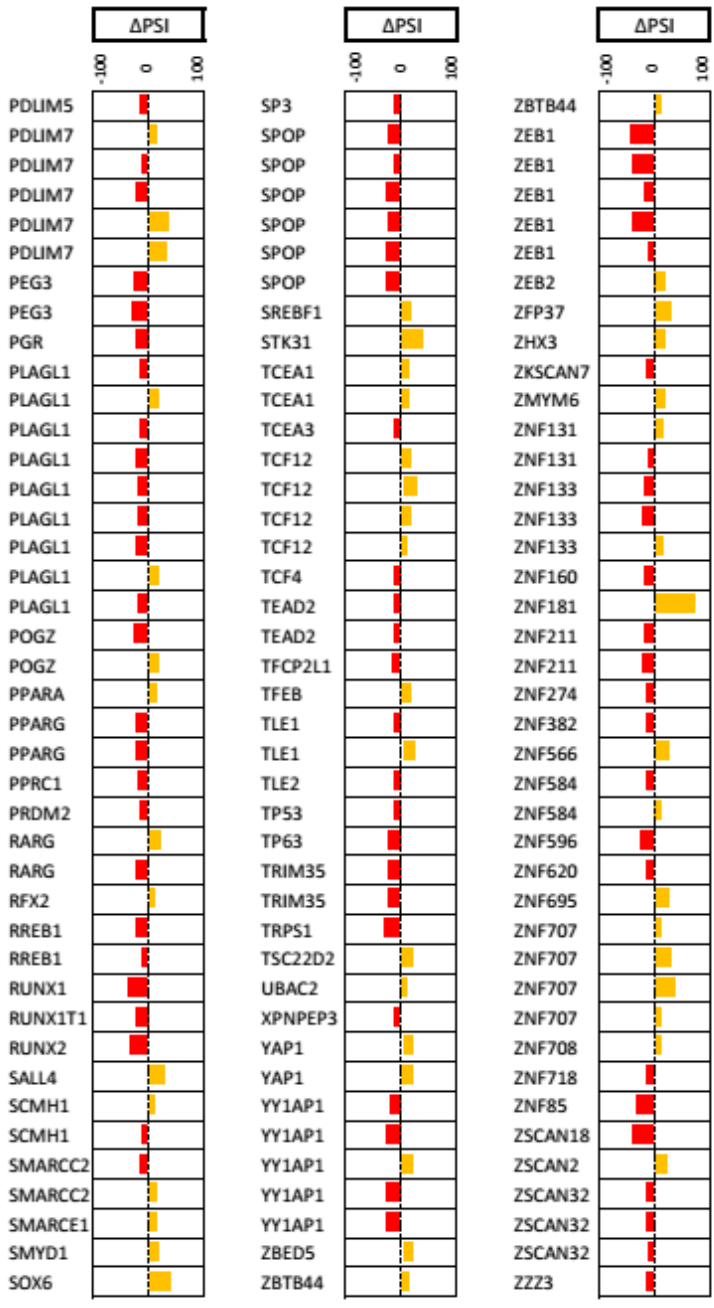